\title{
Methods for Calculating Activation Energy for Portland Cement
}

\author{
by Jonathan L. Poole, Kyle A. Riding, Kevin J. Folliard, Maria C. G. Juenger, and Anton K. Schindler
}

The accurate prediction of thermal gradients in concrete calls for models that characterize the temperature sensitivity of the hydration of cementitious materials. The most common method used for this purpose is the Arrhenius equation, which requires the selection of an activation energy $\mathrm{E}_{\mathrm{a}}$ to define the temperature sensitivity of the reaction. For cementitious materials, $\mathrm{E}_{\mathrm{a}}$ is typically computed using either isothermal calorimetry or compressive strength data. There is disagreement in literature as to the proper method to determine $\mathrm{E}_{\mathrm{a}}$. The $\mathrm{E}_{\mathrm{a}}$ of different cementitious pastes was determined from isothermal calorimeter results using three different computational methods. The results were used to develop a systematic computational method for characterizing $\mathrm{E}_{\mathrm{a}}$ to account for the effect of temperature on the overall rate of hydration of cementitious materials. This work lays the groundwork for more extensive studies to determine the effect of a wide variety of variables on $\mathrm{E}_{\mathrm{a}}$.

Keywords: calorimeter; hydration; portland cement.

\section{INTRODUCTION}

The chemical reactions between cement and water during setting and hardening are exothermic, which results in a rise in the temperature of the hardening concrete. Characterization of temperature rise is useful for a variety of reasons. The curing temperature of concrete is arguably the one variable that has the most significant effect on the rate of hydration. ${ }^{1}$ Early research by Saul ${ }^{2}$ on the effects of temperature on concrete was driven by the desire to predict strength of steam-cured concrete, which led to the development of the "maturity" concept. ASTM C $1074^{3}$ defines maturity as "the extent of the development of a property of a cementitious material." For mass concrete elements, accurate characterization of the progress of hydration is necessary to predict temperature gradients, maximum concrete temperature, thermal stresses, and relevant mechanical properties.

Accurate prediction of temperature development in mass concrete requires knowledge of the adiabatic temperature rise of a particular concrete mixture. Adiabatic calorimetry is the best test to obtain this information. Unfortunately, adiabatic calorimeters are not common. Semi-adiabatic calorimeters are much more common, because the test setup is much simpler. Therefore, semi-adiabatic calorimeters are more commonly used to characterize the heat evolution of a concrete mixture. Corrections must be made to semi-adiabatic temperature measurements to approximate the results obtained from an adiabatic system. ${ }^{4}$ The Arrhenius theory is used to capture the temperature sensitivity of a particular mixture so that its behavior may be modeled under different temperature conditions. In this manner, semi-adiabatic calorimetry data may be used to model what would be experienced under adiabatic conditions.

The Arrhenius equation uses the concept of activation energy $E_{a}$ to define the sensitivity of a particular reaction to temperature. The Arrhenius theory for rate processes is the equation of choice for the study of chemical kinetics, ${ }^{5}$ and is the most commonly used relationship to characterize the temperature sensitivity of portland cement. Portland cement, however, is much more complex than the materials for which the Arrhenius equation was originally developed. Several researchers have discussed determination of the rate constants for use in the Arrhenius equation. ${ }^{6,7}$ Currently, ASTM C $1074^{3}$ uses compressive strength of mortar cubes to determine the activation energy for strength estimating purposes.

The cumulative heat of hydration at a particular point in time relative to the total potential heat of hydration of the system is often used to quantify the degree of hydration. $4,8-11$ Because heat evolution is measured directly with isothermal calorimetry, this test method would seem to be a better indication of the extent of hydration than compressive strength. There are, however, discrepancies in the literature on exactly how to calculate $E_{a}$ from isothermal calorimetry data.

Arrhenius' theory does not describe the temperature sensitivity of the hydration of individual chemical reactions, ${ }^{8}$ but it is probably the best tool available to account for the effect of temperature on the combined rate of hydration due to all chemical reactions. ${ }^{9,10,12}$ Calculations of $E_{a}$ should be robust enough to differentiate between systems with different compositions, supplementary cementing materials, and chemical admixtures. However, they should only be as complex as is warranted to accurately estimate the temperature rise in concrete structures. Therefore, a consistent method is needed to calculate $E_{a}$ from test data.

This paper examines three methods of activation energy calculation: 1) a single linear approximation method that calculates the reaction rate based on a first-order differential rate equation; 2) an incremental method based on the same principles, but with the rate calculated incrementally over the time period of interest; and 3) a method based on modifications of ASTM C $1074^{3}$ using isothermal calorimetry data instead of strength. Each method was investigated in detail, and the advantages and disadvantages of each method are highlighted. Twenty different cementitious mixtures were investigated to determine the best method to calculate the activation energy.

\section{RESEARCH SIGNIFICANCE}

Large thermal gradients in concrete during curing can result in thermal cracking. By accurately predicting thermal

ACI Materials Journal, V. 104, No. 1, January-February 2007.

MS No. M-2006-105.R1 received March 17, 2006, and reviewed under Institute publication policies. Copyright (C) 2007, American Concrete Institute. All rights reserved, including the making of copies unless permission is obtained from the copyright proprietors. Pertinent discussion including authors' closure, if any, will be published in the November-December 2007 ACI Materials Journal if the discussion is received by July $1,2007$. 
ACI member Jonathan L. Poole is a PhD Candidate at the University of Texas at Austin, Austin, Tex. He received a BS and an MS degree from the University of Texas at Austin.

ACI member Kyle A. Riding is a PhD Candidate at the University of Texas at Austin. He received a BS from Brigham Young University, Provo, Utah, and an MS degree from the University of Texas at Austin.

ACI member Kevin J. Folliard is an Associate Professor in the Department of Civil, Architectural, and Environmental Engineering at the University of Texas at Austin. He received his $P h D$ in civil engineering from the University of California at Berkeley, Berkeley, Calif., in 1995. He received the ACI Young Member Award for Professional Achievement in 2002.

ACI member Maria C. G. Juenger is an Assistant Professor of Civil, Architectural, and Environmental Engineering at the University of Texas at Austin. She received a $P h D$ in materials science and engineering from Northwestern University, Evanston, Ill.

ACI member Anton K. Schindler is an Assistant Professor in the Department of Civil Engineering at Auburn University, Auburn, Ala. He received his MSE and PhD in civil engineering from the University of Texas at Austin.

gradients before placement, the engineer has the opportunity to mitigate the risk of thermal cracking. Accurate prediction of thermal gradients in concrete requires an estimate the temperature sensitivity of the hydration of cementitious materials. The most common method used to characterize the temperature sensitivity of the hydration of cementitious materials is the Arrhenius equation, which requires the selection of an $E_{a}$. There are a variety of different computational methods to calculate $E_{a}$, which makes the comparison of results between different studies difficult. Also, the sensitivity of $E_{a}$ to the choice of calculation procedure is unknown. This paper provides guidance on the most appropriate method to determine $E_{a}$ from isothermal calorimetry test results.

\section{BACKGROUND}

Much of the theory still used today to describe the dependency of rate processes on temperature was developed in the late 19th century. The theory of reaction rates used commonly today originated from the work of S. Arrhenius (1889), who developed Eq. (1) to account for the influence of temperature on the rate of inversion of sucrose. ${ }^{13}$ Arrhenius showed that the variation of the specific rate of reaction with the temperature could be expressed as follows

$$
k=A \cdot e^{\frac{-E_{a}}{R T}}
$$

where $R$ equals the natural gas constant $(8.314 \mathrm{~J} / \mathrm{mol} / \mathrm{K}), T$ equals temperature $K$ at which reaction occurs, $k$ equals the rate of heat evolution $W, A$ equals the proportionality constant (same units as $k)$, and $E_{a}$ equals activation energy $(\mathrm{J} / \mathrm{mol})$.

The exponential relationship was based on collision probabilities, thermodynamics, and statistical mechanics for homogenous gas and liquid single-phase reactions. ${ }^{8}$ The Arrhenius equation is by far the most widely used relationship to describe rate processes of chemical reactions. ${ }^{5}$

\section{Calculation of Arrhenius parameters}

The $E_{a}$ of a reaction is intended to represent the energy that a molecule in the initial state of the process must acquire before it can take part in a reaction. ${ }^{13}$ To quantify $E_{a}$, measurements of reaction rates can be made at different isothermal temperatures. Glasstone et al. ${ }^{13}$ define the experimental (or apparent) $E_{a}$ as the activation energy obtained experimentally by plotting the natural $\log$ of reaction rate versus the inverse of the reaction temperature. The value $E_{a}$ may be determined by multiplying the negative of the slope of the best-fit line through $\ln (k)$ versus $1 / T$ by $R$. This interpretation of $E_{a}$ is used to characterize the reaction rate of cementitious materials at various temperatures. The proportionality constant $A$ is determined by taking the exponential of the $y$-axis intercept of the best-fit line. The value $A$ is not typically reported in cement or concrete research, and is not often considered in portland cement hydration, because maturity calculations use ratios of reaction rates- $A$ is therefore cancelled out. The value $E_{a}$ may therefore be calculated independent of $A$ using maturity calculations. ${ }^{14,15}$

\section{Application of Arrhenius theory to cement hydration}

The concept of "equivalent age"16 is necessary to use $E_{a}$ to predict hydration behavior at various curing temperatures. Equation 2, proposed by Frieseleben Hansen and Pederson, ${ }^{16}$ is the most common expression used to compute equivalent age, and is used in the remainder of the paper to model the effects of time and temperature on hydration

$$
t_{e}\left(T_{r}\right)=\sum_{0}^{t} e^{-\frac{E_{a}}{R}\left(\frac{1}{T_{C}}-\frac{1}{T_{r}}\right)} \cdot \Delta t
$$

where $t_{e}\left(T_{r}\right)$ equals equivalent age at reference temperature $T_{r}$ and $T_{c}$ equals temperature of the concrete; $E_{a}$ and $R$ are as defined previously. Note that in this derivation, $E_{a}$ is assumed to be independent of temperature, which is consistent with the Arrhenius theory for rate processes. This is a reasonable approximation, given the relatively small temperature range concrete experiences in most situations. Note that the activation energy recommended by Freiseleben Hansen and Pedersen ${ }^{16}$ is a function of the concrete temperature only for temperatures below $20^{\circ} \mathrm{C}\left(68^{\circ} \mathrm{F}\right)$.

\section{Mechanistic model to quantify heat of hydration}

The progress of the hydration of portland cement may be quantified by the degree of hydration $\alpha$, which varies from 0 to 1 , with a value of 1 indicating complete hydration. For this study, degree of hydration is taken as the ratio of heat evolved at time $t$ to the total amount of heat available, as shown in Eq. (3). , $^{4-11}$

$$
\alpha=\frac{H(t)}{H_{u}}
$$

where $\alpha$ equals the degree of hydration at time $t, H(t)$ equals the heat evolved from time 0 to time $t(\mathrm{~J} / \mathrm{gram})$, and $H_{u}$ equals total heat available for reaction $(\mathrm{J} / \mathrm{gram})$.

The value $H_{u}$ is a function of cement composition and amount and type of supplementary cementing materials (SCMs) and may be calculated as follows ${ }^{17}$

$$
H_{u}=H_{c e m} \cdot P_{c e m}+461 \cdot P_{\text {slag }}+1800 \cdot P_{F A-C a O} \cdot P_{F A}
$$

where $p_{\text {slag }}$ equals slag mass to total cementitious content ratio, $p_{F A}$ equals fly ash mass to total cementitious content ratio, $p_{F A-C a O}$ equals fly ash $\mathrm{CaO}$ mass to total fly ash content ratio, $p_{\text {cem }}$ equals cement mass to total cementitious content ratio, and $H_{c e m}$ equals heat of hydration of the cement (J/gram). 
The value $H_{c e m}$ can be calculated as shown in Eq. (5) ${ }^{17}$

$$
\begin{aligned}
H_{\text {cem }}=500 \cdot P_{C_{3} S}+260 \cdot P_{C_{2} S}+866 \cdot P_{C_{3} A}+420 \cdot P_{C_{4} A F} \\
+624 \cdot P_{S O_{3}}+1186 \cdot P_{\text {Free Ca }}+850 \cdot P_{M g O}
\end{aligned}
$$

where $H_{c e m}$ equals the total heat of hydration of portland cement (J/gram) at $\alpha=1.0$, and $p_{i}$ equals the mass of $i$-th component to total cement content ratio.

A mathematical relationship may be used to model the degree of hydration development. A number of researchers ${ }^{17,18}$ have suggested an exponential function to characterize cement hydration based on degree of hydration data. The most commonly used relationship is a threeparameter model defined in Eq. (6)

$$
\alpha\left(t_{e}\right)=\alpha_{u} \cdot e^{-\left[\frac{\tau}{t_{e}}\right]^{\beta}}
$$

where $\alpha\left(t_{e}\right)$ equals the degree of hydration at equivalent age $t_{e}, t_{e}$ equals the equivalent age determined from Eq. (2) (hours), $\tau$ equals the hydration time parameter (hours), $\beta$ equals the hydration shape parameter, and $\alpha_{u}$ equals the ultimate degree of hydration.

Note that Eq. (6) is an empirical formulation to quantify the degree of hydration behavior of concrete. Nevertheless, in most cases, this formulation provides a reasonable framework for predictive models, because $\alpha_{u}$, $\tau$, and $\beta$ may all be calibrated with test data.

\section{TEST METHODS}

Isothermal calorimetry (also called conduction calorimetry) is used to measure the heat of hydration of a cement paste at a fixed temperature. Temperature in the system is maintained by keeping the sample in a heat sink, typically water, air, or some other conductive medium. As with all experimental methods, isothermal calorimetry has several limitations that should be addressed. After the first few days of hydration, the rate of heat liberation is too low for isothermal calorimetry to be a practical means of investigation. Nevertheless, results are useful for characterizing reaction rate sensitivity during first few days of hydration. The test method's useful duration varies from approximately 2 days to 7 days, depending on the reaction temperature and sample size. For example, the test is quite useful for the investigation of hydration of $\mathrm{C}_{3} \mathrm{~S}$, $\mathrm{C}_{3} \mathrm{~A}$, early hydration of some pozzolans (such as Class $\mathrm{C}$ fly ash), and reactions at high temperatures. However, slower reactions such as those that occur with $\mathrm{C}_{2} \mathrm{~S}$, pozzolanic reactions, or tests at low temperatures may be less accurate, because the signal-to-noise ratio becomes quite low with time. Care should be taken in making judgments about total heat evolved after 72 hours, because bias and error in the system may be of similar magnitude to the heat released by hydration reactions. Finally, it is difficult to use isothermal calorimetry to draw conclusions about the temperature dependency of the individual chemical reactions. These reactions are highly interdependent, and their relative rates are difficult to isolate with this test method.

It should be noted that sample introduction into the calorimeter allows heat in, especially when the testing temperature is significantly different from the ambient temperature. When tests are begun, the calorimeter registers disturbance, and must be allowed to equilibrate before the data can be used. Typically, this equilibration requires about one hour. Therefore, data acquired during this time must be discarded. Characterization of heat output in the first hour may be investigated if water can be introduced and mixed with the dry cementitious material in place, such that calorimeter equilibrium is minimally disturbed.

\section{Experimental program}

During this study, isothermal calorimetry was performed on various cementitious pastes at $41,59,73,100$, and $140{ }^{\circ} \mathrm{F}$ $\left(5,15,23,38\right.$, and $\left.60^{\circ} \mathrm{C}\right)$ using an eight-channel isothermal conduction calorimeter. The calorimeter was kept in a temperature-controlled room at $70^{\circ} \mathrm{F} \pm 5{ }^{\circ} \mathrm{F}\left(21^{\circ} \mathrm{C} \pm 3{ }^{\circ} \mathrm{C}\right)$. Cement pastes were proportioned using a water-to-cementitious material ratio $(w / \mathrm{cm})$ of 0.44 , and using $0.55 \mathrm{lb}(250 \mathrm{~g})$ of cementitious material. Prior to mixing, materials were kept as close as possible to the test temperature. Pastes were mixed in a kitchen blender for approximately 3 minutes. Eight tests were run simultaneously in the isothermal calorimeter. Each test sample had a mass of approximately $0.044 \mathrm{lb}(20 \mathrm{~g})$. Tests were conducted for a duration of 44 hours at $140{ }^{\circ} \mathrm{F}$ $\left(60{ }^{\circ} \mathrm{C}\right)$ to over 100 hours at $41^{\circ} \mathrm{F}\left(5^{\circ} \mathrm{C}\right)$.

The following cementitious materials were used: ASTM Type I cement, ${ }^{19}$ two ASTM Class F fly ashes ${ }^{20}$ (labeled F1 and F2 for this study), two ASTM Class C fly ashes ${ }^{20}$ (labeled $\mathrm{C} 1$ and $\mathrm{C} 2$ for this study), one silica fume, and one ASTM Grade 120 ground-granulated blast-furnace slag (GGBFS). ${ }^{21}$ The accelerator used was an ASTM C 494, ${ }^{22}$ Type $\mathrm{C}$ calcium nitrate-based accelerator. Deionized water was used for mixing. Chemical and physical properties of the materials are summarized in Table 1. Cement phases were calculated from x-ray fluorescence data using the Bogue calculations per ASTM C $150 .{ }^{19}$ Supplementary cementing material (SCM) replacement levels were calculated on a mass basis.

Twenty mixtures were tested:

- Control: 100\% Type I portland cement;

- Type I cement with 20,30, and $40 \%$ of each fly ash type;

- Type I cement with 30, 40, and 50\% GGBFS;

- Type I cement with 5\% silica fume;

- Type I cement with 5\% silica fume and 20\% Class F fly ash;

- Type I cement with $20 \%$ Class F fly ash, and $26 \mathrm{ml} /(\mathrm{kg}$ of cementitious material) $(20 \mathrm{oz} / 100 \mathrm{lb}$ of cementitious material) of accelerator; and

- Type I cement with $30 \%$ Class C fly ash with $26 \mathrm{ml} /(\mathrm{kg}$ of cementitious material) (20 oz/100 lb of cementitious material) of accelerator.

All aforementioned percentages are replacements by mass of cement. For simplicity, only results from four mixtures will be used to illustrate the various methods of calculating the activation energy. These mixtures are 100\% Type I portland cement, $60 \%$ cement with $40 \%$ Class C fly ash C2, $60 \%$ cement with $40 \%$ Class F fly ash F2, and 50\% cement with 50\% Grade 120 GGBFS. These mixtures were chosen for more extensive discussion because they should have sufficiently different hydration behavior. The activation energy results for all mixtures, however, will be presented for completeness. 
Table 1-Chemical and physical properties of cementitious materials

\begin{tabular}{|c|c|c|c|c|c|c|c|}
\hline & & Class I & fly ash & & & & \\
\hline & & F1 & $\mathrm{F} 2$ & $\mathrm{C} 1$ & $\mathrm{C} 2$ & & \\
\hline $\mathrm{SiO}_{2}, \%$ & 19.18 & 56.63 & 51.69 & 37.83 & 33.31 & 94.28 & 34.48 \\
\hline $\mathrm{Al}_{2} \mathrm{O}_{3}, \%$ & 534 & 30.68 & 24.81 & 19.83 & 18.39 & 0.04 & 11.35 \\
\hline $\mathrm{Fe}_{2} \mathrm{O}_{3}, \%$ & 2.30 & 4.94 & 4.22 & 6.17 & 5.40 & 0.06 & 0.67 \\
\hline $\mathrm{CaO}, \%$ & 3.17 & 0.69 & 13.12 & 23.13 & 28.91 & 0.51 & 41.73 \\
\hline $\mathrm{MgO}, \%$ & & 0.73 & 2.29 & 4.62 & 5.25 & 0.57 & 7.32 \\
\hline $\mathrm{Na}_{2} \mathrm{O}, \%$ & 0.12 & 0.12 & 0.18 & 1.74 & 1.64 & 0.06 & 0.14 \\
\hline $\mathrm{K}_{2} \mathrm{O}, \%$ & .95 & 2.26 & 0.84 & 0.057 & 0.35 & 0.99 & 0.38 \\
\hline $\begin{array}{c}\mathrm{Na}_{2} \mathrm{O} \\
\text { equivalent, \% } \\
\end{array}$ & 0.74 & 1.60 & 0.73 & 1.78 & 1.87 & 0.71 & 0.39 \\
\hline $\mathrm{TiO}_{2}, \%$ & 0.26 & 1.61 & 1.54 & 1.44 & 1.51 & 0.02 & 0.46 \\
\hline $\mathrm{MnO}_{2}, \%$ & 0.04 & 0.03 & 0.11 & 0.03 & 0.08 & 0.07 & 0.56 \\
\hline $\mathrm{P}_{2} \mathrm{O}_{5}, \%$ & 0.21 & 0.07 & 0.14 & 1.37 & 1.26 & 0.12 & 0.00 \\
\hline $\mathrm{SrO}, \%$ & 0.09 & 0.07 & 0.22 & 0.42 & 0.51 & 0.01 & 0.10 \\
\hline $\mathrm{BaO}, \%$ & 0.03 & 0.08 & 0.16 & 0.69 & 0.78 & 0.02 & 0.11 \\
\hline $\mathrm{SO}_{3}, \%$ & 3.20 & 0.00 & 0.46 & 1.50 & 2.27 & 0.16 & 1.88 \\
\hline LOI, \% & 4.10 & 2.10 & 0.23 & 0.67 & 0.34 & 3.10 & 0.83 \\
\hline $\begin{array}{l}\text { Insolubl } \\
\text { residue, }\end{array}$ & 0.63 & - & - & - & - & - & - \\
\hline Moisture, \% & - & 0.16 & 0.08 & 0.13 & 0.07 & 1.01 & 0.28 \\
\hline $\mathrm{C}_{3} \mathrm{~S}, \%$ & 63.15 & - & - & - & - & - & - \\
\hline $\mathrm{C}_{3} \mathrm{~A}, \%$ & 10.96 & - & - & - & - & - & - \\
\hline $\mathrm{C}_{2} \mathrm{~S}, \%$ & 7.34 & - & - & - & - & - & - \\
\hline $\mathrm{C}_{4} \mathrm{AF}, \%$ & 7.00 & - & - & - & - & - & - \\
\hline $\begin{array}{c}\text { Blaine } \\
\text { fineness, } \mathrm{m}^{2} / \mathrm{kg}\end{array}$ & 390.9 & 147.3 & 165.5 & 348.4 & 299.9 & $\sim 20,000$ & 331.6 \\
\hline
\end{tabular}

Note: LOI $=$ loss on ignition.

\section{RESULTS AND DISCUSSION}

Figure 1(a) shows heat evolution data from isothermal tests at $73{ }^{\circ} \mathrm{F}\left(23{ }^{\circ} \mathrm{C}\right)$ for Type I portland cement, $60 \%$ Type I cement with $40 \%$ fly ash F2, 60\% Type I cement with $40 \%$ fly ash C2, and 50\% Type I cement with 50\% GGBFS. Figure 1(b) shows cumulative heat evolved at $73{ }^{\circ} \mathrm{F}\left(23{ }^{\circ} \mathrm{C}\right)$ for each of these mixtures. Data are normalized per gram of cementitious material. Heat evolution data at every isothermal temperature for the four mixtures are shown in Fig. 2(a) through (d).

The following must be noted for each of the calculation methods presented in this study:

1. The value $H_{\text {cem }}$ is based on models for pure portland cement developed by Bogue in the 1950s. ${ }^{22}$ The effects of pozzolans, chemical admixtures, and newer cement production methods on $H_{u}$ are either unknown or are less widely published.

2. For this study, calorimeter results during the first hour after mixing are discarded because the calorimeter is still equilibrating. Therefore, the heat of wetting is neglected and cumulative heat evolved $H(t)$ may be slightly lower than actual. It is assumed that degree of hydration for all temperatures begins at zero after approximately 1 hour has elapsed.

3. The value $H_{u}$ is assumed to be independent of the isothermal reaction temperature, as described in KadaBenameur et al. ${ }^{9}$
4. The model assumes independent, fractional contributions of heat from each compound in a cementitious system.

\section{Single linear approximation of reaction rate to determine activation energy}

The following section investigates the use of a first-order (or linear) approximation of reaction rate to calculate $E_{a}$. The reaction rate is calculated using a single, best-fit line of the linear, acceleration phase region of an isothermal test, as discussed by Ma et al. ${ }^{7}$ In some cases, a single linear approximation of the maximum reaction rate is sufficient to quantify the temperature sensitivity of a particular reaction. This is equivalent to calculating the reaction rate using a first-order differential rate equation. ${ }^{13}$ It has been shown, however, that $E_{a}$ of portland cement is highly dependent on degree of hydration. 8,9 Nevertheless, discussion of the simplified, single-point, linear approximation method is warranted to compare various methods that have been used.

Isothermal calorimeter tests were conducted on cementitious paste samples as shown in Fig. 1 and 2. A least-squares, linear fit of the heat evolution data was performed to determine the maximum rate of hydration in the acceleration phase that occurs just prior to the occurrence of the peak heat of hydration. The calculation was repeated for each isothermal test temperature. The procedure is graphically illustrated in Fig. 3 for Type I portland cement. The slope of each least-squares line in Fig. 3(a) defines the reaction rate $k$ at that temperature. Figure 3(b) shows the plot of $\ln (k)$ versus the inverse of the absolute temperature used to determine $E_{a}$. Note that the $y$-axis on Fig. 3(a) was truncated at $10 \mathrm{~J} / \mathrm{gram}$ to better show the data at lower temperatures.

Figure 3 and Table 2 illustrate the calculation of $k$ using the best-fit line from the dormant period of hydration to the

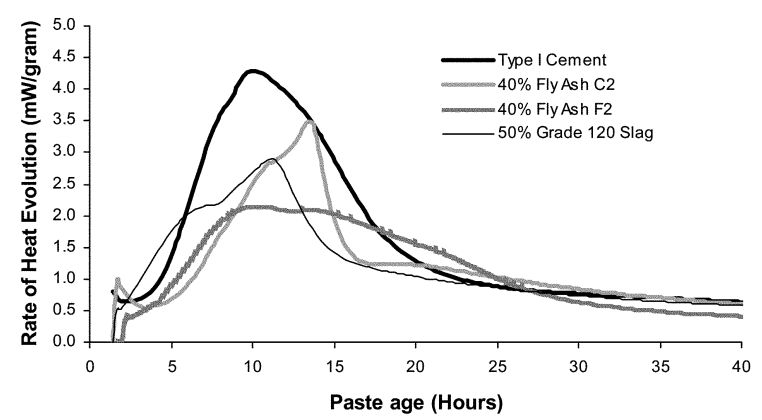

(a)

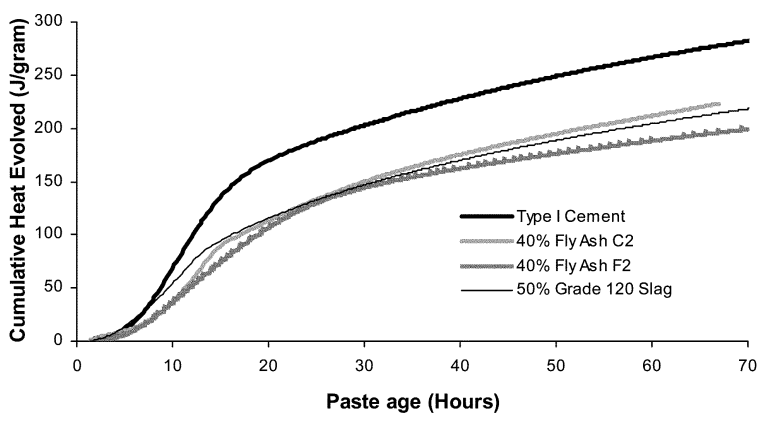

(b)

Fig. 1-(a) Rate of heat evolved per gram of cementitious material; and (b) cumulative heat evolved per gram of cementitious material for four model mixtures at $73{ }^{\circ} \mathrm{F}\left(23^{\circ} \mathrm{C}\right)$. 
first peak of hydration. Determination of the "linear" portion of the heat evolution curve is somewhat subjective because $\mathrm{C}_{3} \mathrm{~S}$ and $\mathrm{C}_{3} \mathrm{~A}$ hydration exhibit discernable peaks in some mixtures at different times. Typically, two large hydration peaks are apparent in the results, as in the $100{ }^{\circ} \mathrm{F}\left(38^{\circ} \mathrm{C}\right)$ sample in Fig. 3(a). In these cases, the determination of $E_{a}$ is relatively straightforward. For some mixtures, however, there may be more than one best fit slope, especially for mixtures where maximum rate of heat evolution is difficult

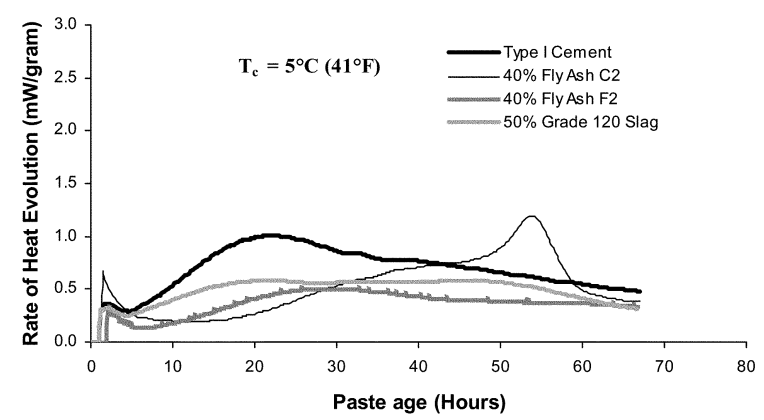

(a)

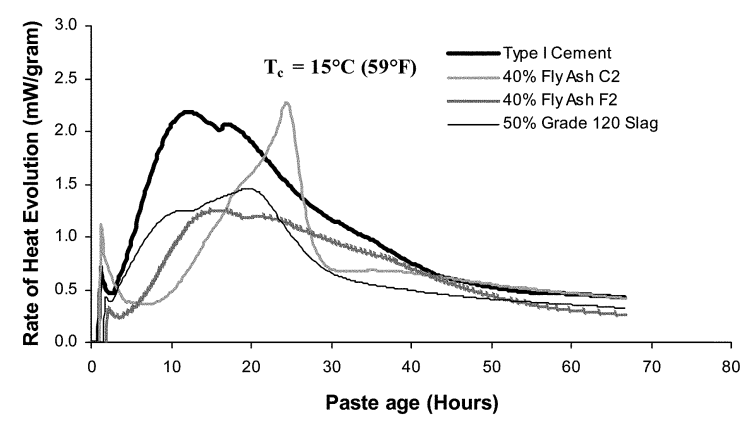

(b)

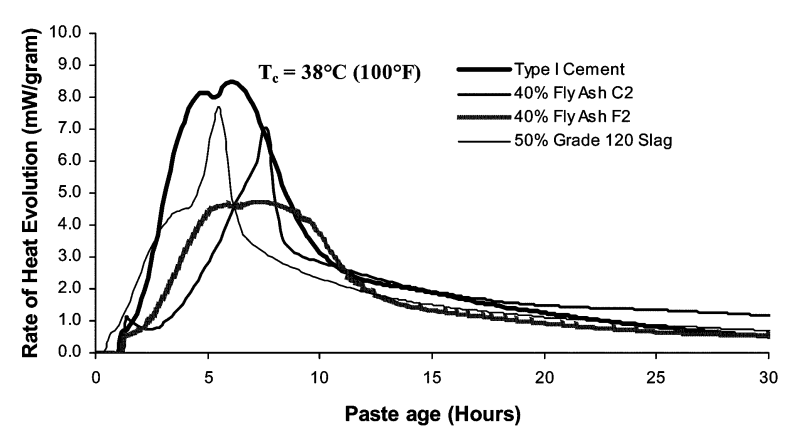

(c)

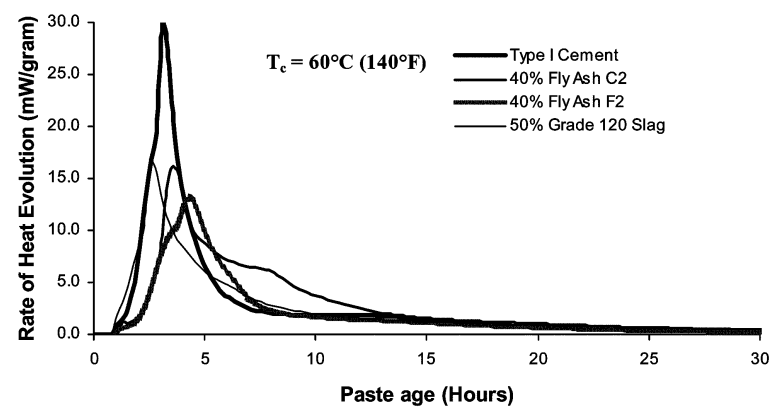

(d)

Fig. 2-Rate of heat evolution for: (a) $41^{\circ} \mathrm{F}\left(5^{\circ} \mathrm{C}\right)$; (b) $59^{\circ} \mathrm{F}$ $\left(15^{\circ} \mathrm{C}\right)$; (c) $100^{\circ} \mathrm{F}\left(38^{\circ} \mathrm{C}\right)$; and (d) $140^{\circ} \mathrm{F}\left(60^{\circ} \mathrm{C}\right)$. to determine (such as at low temperatures, or where the $\mathrm{C}_{3} \mathrm{~S}$ and $\mathrm{C}_{3} \mathrm{~A}$ peaks overlap). The variability in $E_{a}$ depends on the magnitude and timing of the $\mathrm{C}_{3} \mathrm{~A}$ and $\mathrm{C}_{3} \mathrm{~S}$ peaks. A linear least-squares line adequately fits the heat evolution data for the pastes containing pure cement and Class $\mathrm{F}$ fly ash evaluated herein. For the mixtures investigated in this paper that contained GGBFS or Class C fly ash, however, a single, best-fit line was not sufficient to calculate $E_{a}$, because the determination of the appropriate reaction rate was difficult.

Other problems with the single linear approximation method include the difficultly in uniquely identifying the start of the acceleration period at low temperatures. In addition, data at higher degrees of hydration are neglected entirely by using only the rate of reaction during the accelerating phase. The method is the most convenient of the three presented in this paper. However, the subjectivity of this method limits the conclusions that may be drawn about the temperature sensitivity of a particular mixture, as well as the accuracy of any prediction. Therefore, a more accurate method of $E_{a}$ calculation using a higher order or integrated approximation of reaction rate is desired.

\section{Incremental calculation of activation energy}

Cement is composed of a number of different compounds that react at different rates, so it is possible that the $E_{a}$ may vary considerably as the cementitious material hydrates. Furthermore, hydration is initially reaction-rate-limited and becomes diffusion-limited as solid hydration products form. Several researchers have cited these reasons to claim a dependence of $E_{a}$ on degree of hydration $\alpha .{ }^{8,9}$ An incremental calculation method highlights how $E_{a}$ is influenced by the progress of hydration. The following section will show a differential first order rate approximation, calculated

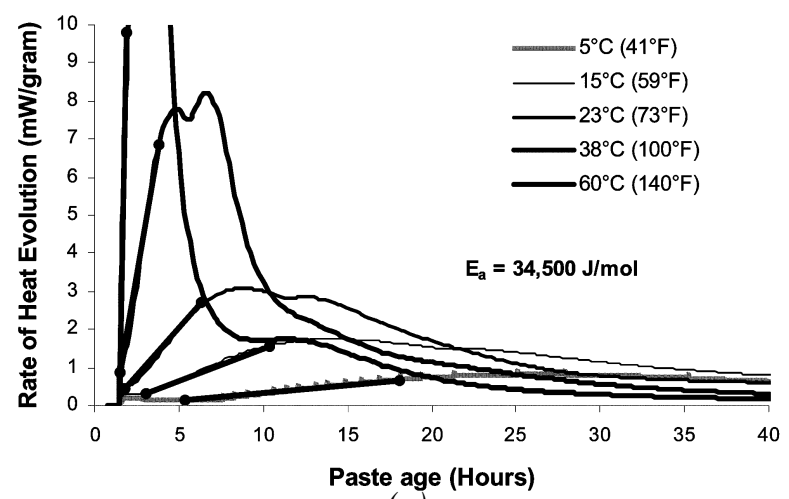

(a)

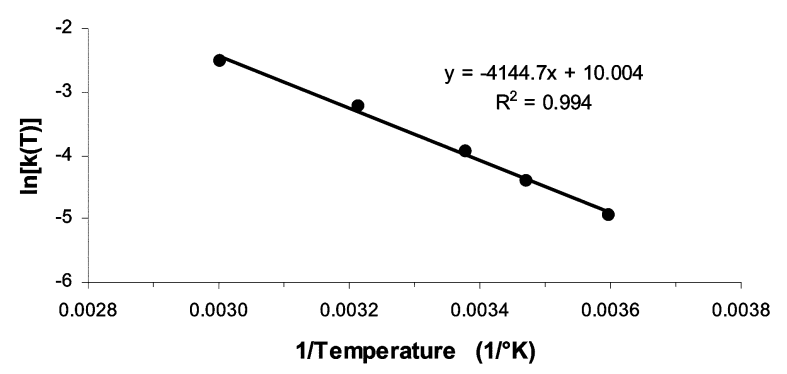

(b)

Fig. 3-(a) Determination of $\mathrm{k}$ using linear fit for 100\% Type I cement; and $(b) \mathrm{E}_{\mathrm{a}}$ from plot of $\ln (\mathrm{k})$ versus $1 / \mathrm{T}$. 
incrementally, that is, at each point where heat evolution was measured.

The value $E_{a}$ may be determined at any age if reaction rates at different test temperatures $k(T)$ are computed at a constant $\alpha$. Isothermal calorimeters may be calibrated such that the power necessary to maintain isothermal conditions $P(t)$ may be continuously measured. The following equations show the relationship between $\alpha, k(T)$, and $P(t)$. First, $k(T)$ may be related to change in $\alpha$ as follows 9

$$
k(T) \cdot f(\alpha)=\left(\frac{d \alpha}{d t}\right)_{T}
$$

where $k(T)$ equals the reaction rate $\mathrm{J} / \mathrm{s}, f(\alpha)$ equals the function depending on degree of hydration $1 / \mathrm{J}, \alpha$ equals the degree of hydration as in Eq. (3), and $d \alpha / d t$ equals the rate of change of degree of hydration $1 / \mathrm{s}$.

If a mixture has a fixed total amount of heat available for reaction $H_{u}$, then change in $\alpha$ may be related to $P(t)$ by ${ }^{9} \mathrm{Eq}$. (8).

$$
\frac{d \alpha}{d t}=\frac{1}{H_{u}} \cdot\left(\frac{d H(t)}{d t}\right)=\frac{P(t)}{H_{u}}
$$

where $H_{u}$ equals the total heat available for reaction, and $H(t)$ equals the cumulative heat evolved at time $t$.

To calculate $E_{a}$ at any $\alpha$, incremental reaction rates are needed at $\alpha$ for all test temperatures $T$. Reaction rate and power are essentially one and the same, presuming the calorimeter has been calibrated properly. Reaction rates and power may be related as shown in Eq. (9). ${ }^{9}$

$$
k(T)=\frac{1}{H_{u}} \cdot\left[\frac{P(t)}{f(\alpha)}\right]_{T}=P(\alpha, T)
$$

where $P(\alpha, T)$ equals the power measured for a given $\alpha, T$.

Several researchers ${ }^{8,9}$ have used this procedure to calculate $E_{a}$ (for two temperatures) over a range of $\alpha$. The value $E_{a}$ may be calculated for any number of temperatures using a least squares best-fit line at each degree of hydration. Equation 10 computes $E_{a}$ continuously as a function of degree of hydration. Calibrated power output, isothermal temperature, and time are readily available from an isothermal calorimeter.

$$
E_{a}(\alpha)=\frac{n \sum_{1}^{n} \frac{1}{T_{n}} \cdot \ln \left(P\left(\alpha, T_{n}\right)\right)-\sum_{1}^{n} \frac{1}{T_{n}} \cdot \sum_{1}^{n} \frac{1}{\ln \left(P\left(\alpha, T_{n}\right)\right)}}{n \sum_{1}^{n}\left(\frac{1}{T_{n}}\right)^{2}-\left(\sum_{1}^{n} \frac{1}{T_{n}}\right)^{2}} \cdot R(10)
$$

where $T_{n}$ equals Isothermal test temperature (different for each test $n$ ).

The value $E_{a}$ was calculated at various $\alpha$ for four of the mixtures tested during this study. Results are shown in Fig. 4 and Table 2 for these mixtures. Figure 4 shows that $E_{a}$ strongly depends on $\alpha$. Several interesting observations may be made when the heat evolution results are compared with the activation energy calculations at various $\alpha$. For Type I portland cement, $E_{a}$ rises as high as 55,660 J/mol, (corresponding to the second

\begin{tabular}{|c|c|c|c|c|c|c|c|c|c|c|c|}
\hline \multirow[b]{2}{*}{ Mixture } & \multirow[b]{2}{*}{$\begin{array}{c}T, \\
{ }^{\circ} \mathrm{F}\left({ }^{\circ} \mathrm{C}\right)\end{array}$} & \multicolumn{3}{|c|}{ Linear method } & \multicolumn{5}{|c|}{ Modified ASTM C 1074} & \multicolumn{2}{|c|}{$\begin{array}{l}\text { Incremental } \\
\text { method }\end{array}$} \\
\hline & & $\begin{array}{c}\text { Reaction rate } \\
\ln (k)\end{array}$ & $\begin{array}{c}E_{a} \\
\mathrm{~J} / \mathrm{mol}\end{array}$ & $R^{2^{*}}$ & $\alpha_{u}$ & $\beta$ & $\tau$, hours & $\begin{array}{c}E_{a}, \\
\mathrm{~J} / \mathrm{mol}\end{array}$ & $R^{2 \dagger}$ & $\begin{array}{c}E_{a}, \\
\mathrm{~J} / \mathrm{mol}\end{array}$ & $R^{2 \dagger}$ \\
\hline \multirow{5}{*}{$\begin{array}{l}\text { Type I } \\
\text { cement }\end{array}$} & $41(5)$ & $1.11 \mathrm{E}-5$ & \multirow{5}{*}{34,500} & \multirow{5}{*}{0.994} & \multirow{5}{*}{0.648} & \multirow{5}{*}{0.968} & 57.06 & \multirow{5}{*}{40,500} & 0.849 & \multirow{5}{*}{ Varies } & 0.985 \\
\hline & $59(15)$ & $3.83 \mathrm{E}-05$ & & & & & 28.07 & & 0.994 & & 0.994 \\
\hline & $73(23)$ & $1.16 \mathrm{E}-04$ & & & & & 16.52 & & 0.999 & & 0.992 \\
\hline & $100(38)$ & 5.91E-04 & & & & & 6.74 & & 0.990 & & 0.986 \\
\hline & $140(60)$ & $3.02 \mathrm{E}-03$ & & & & & 3.25 & & 0.959 & & 0.978 \\
\hline \multirow{5}{*}{$\begin{array}{c}40 \% \\
\text { fly ash } \\
\text { F2 }\end{array}$} & $41(5)$ & 4.87E-06 & \multirow{5}{*}{32,800} & \multirow{5}{*}{0.989} & \multirow{5}{*}{0.654} & \multirow{5}{*}{1.031} & 69.33 & \multirow{5}{*}{36,700} & 0.374 & \multirow{5}{*}{ Varies } & 0.831 \\
\hline & $59(15)$ & $2.39 \mathrm{E}-05$ & & & & & 29.82 & & 0.987 & & 0.986 \\
\hline & $73(23)$ & $6.16 \mathrm{E}-05$ & & & & & 18.03 & & 0.998 & & 0.981 \\
\hline & $100(38)$ & $1.95 \mathrm{E}-04$ & & & & & 8.58 & & 0.992 & & 0.968 \\
\hline & $140(60)$ & $1.30 \mathrm{E}-03$ & & & & & 4.88 & & 0.937 & & 0.992 \\
\hline \multirow{5}{*}{$\begin{array}{l}40 \% \\
\text { fly ash } \\
\text { C2 }\end{array}$} & $41(5)$ & $5.94 \mathrm{E}-06$ & \multirow{5}{*}{33,100} & \multirow{5}{*}{0.980} & \multirow{5}{*}{0.704} & \multirow{5}{*}{0.874} & 77.05 & \multirow{5}{*}{37,600} & 0.986 & \multirow{5}{*}{ Varies } & 0.926 \\
\hline & $59(15)$ & $2.76 \mathrm{E}-05$ & & & & & 42.71 & & 0.991 & & 0.991 \\
\hline & $73(23)$ & $9.24 \mathrm{E}-05$ & & & & & 27.67 & & 0.977 & & 0.958 \\
\hline & $100(38)$ & $2.00 \mathrm{E}-04$ & & & & & 13.15 & & 0.992 & & 0.990 \\
\hline & $140(60)$ & $1.77 \mathrm{E}-03$ & & & & & 5.25 & & 0.986 & & 1.000 \\
\hline \multirow{5}{*}{$\begin{array}{c}50 \% \\
\text { Grade } \\
120 \\
\text { slag }\end{array}$} & $41(5)$ & $6.00 \mathrm{E}-06$ & \multirow{5}{*}{35,100} & \multirow{5}{*}{0.987} & \multirow{5}{*}{0.756} & \multirow{5}{*}{0.650} & 86.97 & \multirow{5}{*}{39,900} & 0.958 & & 0.978 \\
\hline & $59(15)$ & $2.64 \mathrm{E}-05$ & & & & & 53.28 & & 0.894 & & 0.977 \\
\hline & $73(23)$ & $6.67 \mathrm{E}-05$ & & & & & 26.88 & & 0.998 & Varies & 0.988 \\
\hline & $100(38)$ & $1.78 \mathrm{E}-04$ & & & & & 13.42 & & 0.988 & & 0.997 \\
\hline & $140(60)$ & $2.51 \mathrm{E}-03$ & & & & & 5.23 & & 0.962 & & 0.954 \\
\hline
\end{tabular}
major hydration peak, generally due to $\mathrm{C}_{3} \mathrm{~A}$ ), and then decreases significantly. Mixtures containing Class $\mathrm{C}$ fly ash

Table 2-Comparison of $E_{a}$ calculation methods

${ }^{*} R^{2}$ of least squares best-fit line of $\ln (k)$ versus $1 / T$.

${ }^{\dagger} R^{2}$ of least squares best-fit line of three parameter exponential model versus measured heat of hydration. 
C2 and Grade 120 GGBFS show different activation energy behavior. For $40 \%$ Class $\mathrm{C}$ fly ash $\mathrm{C} 2, E_{a}$ shows a significant drop corresponding with the $\mathrm{C}_{3} \mathrm{~A}$ peak. The mixture with $50 \%$ Grade 120 GGBFS shows a smaller decrease at the same $\alpha$.

Once $E_{a}$ has been calculated for a range of $\alpha$, it can be used to predict heat evolution using equivalent age concepts shown in Eq. (2) through (6). This predicted heat evolution may then be compared with the measured heat evolution to evaluate the accuracy of the calculated $E_{a}$. Figure 5 compares measured degree of hydration to the degree of hydration computed for Type I portland cement using a variable $E_{a}$, equivalent age, and the three-parameter exponential relationship for hydration, as calculated in Eq. (2) through (6). Coefficient of determination $R^{2}$ values, which compare measured $\alpha$ to calculated $\alpha$, are presented in Table 2 for the incremental method. The $R^{2}$ values range from 0.831 to 1.000 for all mixtures at $41,59,73,100$, and $140{ }^{\circ} \mathrm{F}(5,15$, 23,38 , and $60{ }^{\circ} \mathrm{C}$ ). Therefore, $E_{a}$ models hydration fairly well at these temperatures.

In spite of the good results shown in Fig. 5 and Table 2, there are several problems with the incremental method. First, the method is quite sensitive to errors in measurement and calculation. For example, heat added to the system during mixing (prior to placement in the calorimeter) may change the time at which $\mathrm{C}_{3} \mathrm{~S}$ or $\mathrm{C}_{3} \mathrm{~A}$ will appear to hydrate. If this error is not constant from test to test, reactions will seem to begin at different degrees of hydration. This introduces unwanted subjectivity into the calculation. Additionally, the method is quite sensitive to measurement bias and precision, especially at low temperatures. Next, the calculation of $\alpha_{u}$ is

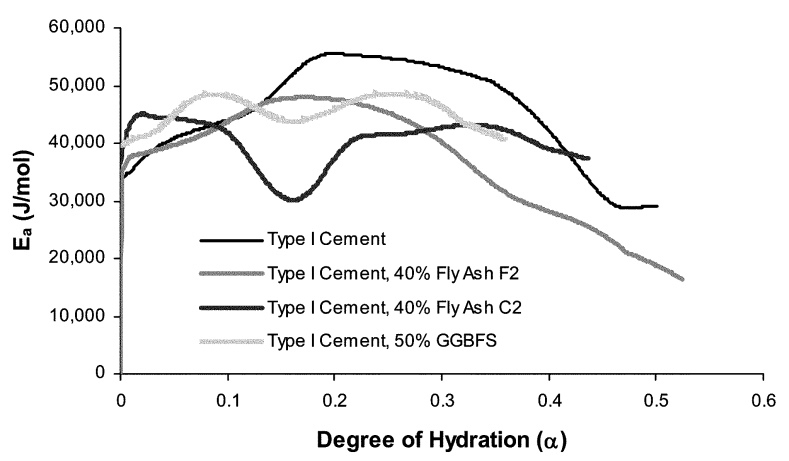

Fig. 4-Incremental $\mathrm{E}_{\mathrm{a}}$ calculation.

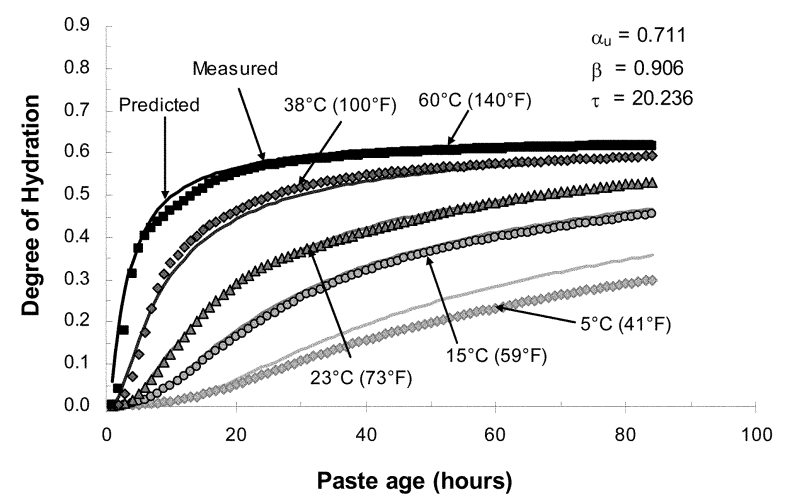

Fig. 5-Hydration prediction using variable $\mathrm{E}_{\mathrm{a}}$ for Type I portland cement. necessary for the purposes of curve fitting to Eq. (6). The accuracy of $\alpha_{u}$ from isothermal calorimetry compared with $\alpha_{u}$ determined from other established methods, such as chemicallybound water, is questionable, because hydration data is only available for the first few days after mixing. Heat evolved after the first few days is neglected in the isothermal test. Furthermore, it is debatable whether the increased accuracy due to using the incremental method is necessary for heat transfer and hydration modeling given the variability in other parts of a heat transfer and hydration model. Finally, the incremental method produces a variable $E_{a}$, which is not easily quantifiable and makes the development of mechanistic models of hydration development mathematically very difficult.

\section{Calculation of activation energy using modification of ASTM C 1074}

As discussed in the previous two sections, the differential first order rate approximation has some drawbacks, either when done with a single line or incrementally. Reaction rates may be also modeled using an integrated approximation. This method is discussed in this section.

Tank and Carino ${ }^{15}$ proposed the procedure incorporated in ASTM C $1074^{3}$ to calculate $E_{a}$. The procedure in ASTM C 1074 uses mortar strength data from samples cured at three different isothermal temperatures to determine the activation energy. To calculate $E_{a}$ using isothermal calorimetry data rather than strength data, researchers ${ }^{1,23}$ derived a procedure that is very similar to the one contained ASTM C 1074. ASTM C 1074 uses a rational, asymptotic model to describe strength development. One limitation of the asymptotic function is that it assumes zero gain in the property under investigation up until setting time is reached. This limitation does not model the hydration behavior as well as an exponential model. Therefore, a three-parameter exponential function (Eq. (6)) was selected to model hydration for this study. ${ }^{1}$

The relationship between $\tau$ at the reference temperature and $\tau$ at the test temperature is equivalent to the relationship between $t$ and $t_{e}$, as expressed in Eq. (11) ${ }^{1}$

$$
\frac{t_{e}}{t}=f\left(T_{c}\right)=\frac{k\left(T_{c}\right)}{k\left(T_{r e f}\right)}=\frac{\tau_{c}}{\tau_{r e f}}
$$

where $\tau$ equals chronological age, $\tau_{e}$ equals the equivalent age by Eq. (2), $f\left(T_{c}\right)$ equals the age conversion factor, $k\left(T_{c}\right)$ equals the reaction rate at temperature of concrete $T_{c}, k\left(T_{r e f}\right)$ equals the reaction rate at reference temperature $T_{r e f}, \tau_{c}$ equals the hydration time parameter at temperature of concrete $T_{c}$, and $\tau_{\text {ref }}$ equals the hydration time parameter at reference temperature $T_{r e f}$. The following equation can be derived from Eq. (1) and (11) to calculate $E_{a}{ }^{1}$

$$
E_{a}=-\frac{\ln \left(\frac{\tau_{r e f}}{\tau_{c}}\right)}{\left(\frac{1}{T_{r e f}}-\frac{1}{T_{c}}\right)} \cdot R
$$

where $E_{a}, t, T_{r e f}, T_{c}$, and $R$ are as defined previously.

The value $E_{a}$ is calculated as follows:

- Time and heat evolution data from isothermal calorimeter tests are collected for the sample at different temperatures: $41,59,73,100$, and $140^{\circ} \mathrm{F}\left(5,15,23,38\right.$, and $\left.60{ }^{\circ} \mathrm{C}\right)$ for this study. 
- $\quad$ The data are fit to Eq. (12) at each temperature by solving for $\alpha_{u}$, $\tau$, and $\beta$ using a least squares fit of the exponential function (Eq. (6)).

- The values $\alpha_{u}$ and $\beta$ are presumed independent of the test temperature.

- $\quad \ln (\tau)$ versus $1 /$ Temperature $\left({ }^{\circ} \mathrm{K}\right)$ is plotted as shown in Fig. 3(b). The value $E_{a}$ is the slope of the best-fit line times the negative of the natural gas constant $R$.

Two additional details of the procedure should be noted. First, as with the incremental calculation method, the estimation of $\alpha_{u}$ that is necessary for the purposes of curve fitting, may not compare well with long term measures of degree of hydration, such as chemically-bound water. The same may be said of the ultimate strength $S_{u}$ in the ASTM C 1074 procedure, as $S_{u}$ is obtained from the best-fit of the strength data. Second, $\alpha_{u}$ and $\beta$ are calculated from least squares fit of all of the data, not just the data at the reference temperature as is done in ASTM C 1074. This provides better overall prediction of hydration at all temperatures.

Table 2 summarizes detailed results for the four selected mixtures, as well as the curve-fit parameters that are used to determine $E_{a}$. Equations (2) through (6) are evaluated with the calculated $E_{a}$ to determine $\alpha$. The $R^{2}$ values, which compare measured $\alpha$ to calculated $\alpha$, are presented in Table 2 for the modified ASTM C 1074 method. This evaluates how well the calculated $E_{a}$ actually predicts the measured hydration of various cementitious materials systems at different temperatures. The $R^{2}$ values range from 0.959 to 0.999 for all mixtures at $59,73,100$, and $140{ }^{\circ} \mathrm{F}\left(15,23,38\right.$, and $\left.60{ }^{\circ} \mathrm{C}\right)$. Figure 6(a) and (b) summarizes the results of the modified

Table 3- $E_{a}$ calculation using modified ASTM C 1074 method for all mixtures

\begin{tabular}{|c|c|c|c|c|c|c|c|c|}
\hline SCM & $\begin{array}{c}\mathrm{SCM} \\
\mathrm{CaO}, \\
\%\end{array}$ & $\begin{array}{l}\% \text { by } \\
\text { mass }\end{array}$ & \begin{tabular}{|c|} 
Acceler- \\
ator, \\
$\mathrm{ml} / \mathrm{kg}$ \\
\end{tabular} & $\alpha_{u}$ & $\beta$ & $\begin{array}{c}t, \\
\text { hours }\end{array}$ & $R^{2^{*}}$ & $\begin{array}{c}E_{a}, \\
\mathrm{~J} / \mathrm{mol}\end{array}$ \\
\hline None & - & - & - & 0.651 & 0.946 & \begin{tabular}{|l|}
16.449 \\
\end{tabular} & 0.988 & 40,540 \\
\hline Fly ash F1 & 0.7 & 20 & - & 0.763 & 0.831 & 16.310 & 0.977 & 33,168 \\
\hline Fly ash F1 & 0.7 & 30 & - & 0.818 & 0.783 & 19.387 & 0.991 & 33,974 \\
\hline Fly ash F1 & 0.7 & 40 & - & 0.827 & 0.813 & \begin{tabular}{|l|}
18.258 \\
\end{tabular} & 0.984 & 32,805 \\
\hline Fly ash F2 & 13.1 & 20 & - & 0.688 & 0.909 & 16.880 & 0.959 & 38,192 \\
\hline Fly ash F2 & 13.1 & 30 & - & 0.688 & 0.895 & 18.718 & 0.981 & 36,523 \\
\hline Fly ash F2 & 13.1 & 40 & - & 0.620 & 1.031 & 18.026 & 0.965 & 36,707 \\
\hline Fly ash C1 & 23.1 & 20 & - & 0.688 & 0.962 & \begin{tabular}{|l|}
19.266 \\
\end{tabular} & 0.971 & 34,437 \\
\hline Fly ash C1 & 23.1 & 30 & - & 0.681 & 0.950 & 21.918 & 0.989 & 35,836 \\
\hline Fly ash C1 & 23.1 & 40 & - & 0.678 & 0.938 & 25.369 & 0.992 & 36,747 \\
\hline Fly ash C2 & 28.9 & 20 & - & 0.657 & 0.993 & 18.787 & 0.982 & 32,537 \\
\hline Fly ash C2 & 28.9 & 30 & - & 0.668 & 0.989 & 21.549 & 0.993 & 33,550 \\
\hline Fly ash C2 & 28.9 & 40 & - & 0.704 & 0.874 & 27.665 & 0.999 & 37,583 \\
\hline Slag & - & 30 & - & 0.682 & 0.817 & \begin{tabular}{|l|}
17.554 \\
\end{tabular} & 0.992 & 37,080 \\
\hline Slag & - & 40 & - & 0.707 & 0.734 & 21.232 & 0.995 & 36,936 \\
\hline Slag & - & 50 & - & 0.756 & 0.650 & 26.880 & 0.994 & 39,928 \\
\hline Silica fume & - & 5 & - & 0.649 & 1.102 & \begin{tabular}{|l|}
14.084 \\
\end{tabular} & 0.937 & 31,060 \\
\hline \multirow{2}{*}{$\begin{array}{l}\text { Fly ash F1 } \\
\text { and } \\
\text { silica fume }\end{array}$} & 0.7 & 20 & - & \multirow{2}{*}{0.759} & \multirow{2}{*}{0.838} & \multirow{2}{*}{15.665} & \multirow{2}{*}{0.966} & \multirow{2}{*}{30,507} \\
\hline & - & 5 & - & & & & & \\
\hline Fly ash F2 & 13.1 & 20 & $26\left(20^{\dagger}\right)$ & 0.714 & 0.979 & 19.920 & 0.999 & 32,572 \\
\hline Fly ash C1 & 23.1 & 30 & $26\left(20^{\dagger}\right)$ & 0.784 & 0.920 & 25.428 & 0.993 & 30,027 \\
\hline
\end{tabular}

ASTM C 1074 method for Type I portland cement. These figures show that the accuracy of the modified ASTM C 1074 procedure is comparable to that of the incremental calculation procedure. At $41^{\circ} \mathrm{F}\left(5^{\circ} \mathrm{C}\right)$, however, $R^{2}$ values range from 0.374 to 0.983 , which indicates less accurate prediction of hydration. The loss of accuracy at $41^{\circ} \mathrm{F}\left(5^{\circ} \mathrm{C}\right)$ is likely attributable to a low signal-to-noise ratio in the calorimeter at this low temperature.

The primary advantage of this method over the original ASTM C 1074 is that reaction rates are determined from calorimeter data rather than from strength data. Therefore, both precision and accuracy of the results should be improved when the temperature sensitivity of the hydration reaction is to be determined. Other than the substitution of the exponential (Eq. (6)) for the asymptotic relationship for hydration development and calorimetry data for strength data, the calculation procedure is based on similar concepts to those in ASTM C 1074.

There are several advantages to using the modified ASTM C 1074 for rate $k$ calculation. The method is, on the whole, more systematic than either the linear or incremental methods presented previously. More importantly, an integrated first order approximation of rate of reaction, as used in the modified ASTM C 1074 method, seems to model cement hydration as effectively as the incremental method. The incremental method, however, predicts heat evolution slightly more accurately than the modified ASTM C 1074 method for the four chosen mixtures over the range of temperatures investigated; accuracy is more noticeably improved at 41 and $140^{\circ} \mathrm{F}\left(5\right.$ and $\left.60^{\circ} \mathrm{C}\right)$.

\section{Comparisons with reported values of $\boldsymbol{E}_{\boldsymbol{a}}$}

The value $E_{a}$ was calculated for all twenty mixtures using the modified ASTM C 1074 method, as shown in Table 3. The $R^{2}$ for all of the mixtures was good $(>0.94)$. The $E_{a}$ values presented in Table 3 fall within a narrow range. When compared with values presented in literature, they agree

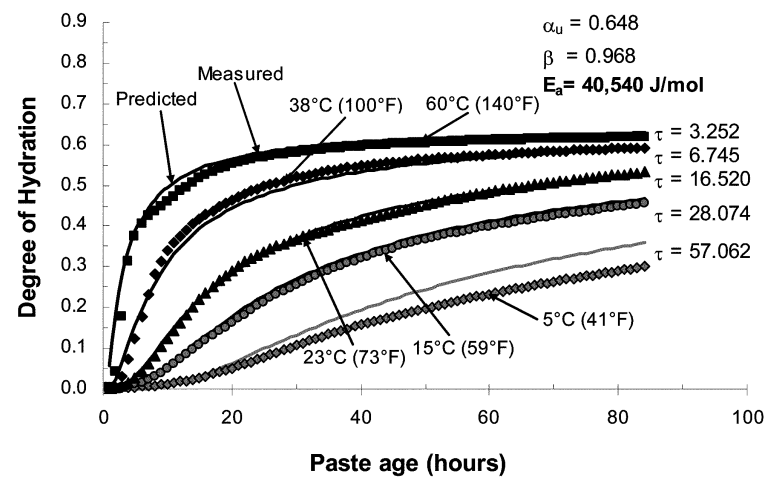

(a)

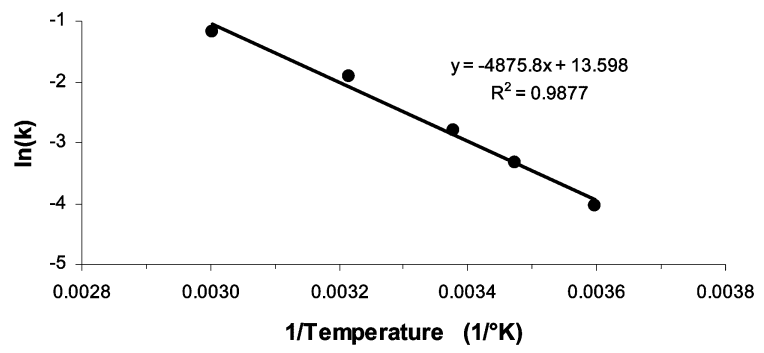

(b)

Fig. 6-(a) Predicted degree of hydration versus actual heat of hydration for 100\% Type I cement using modified ASTM $C 1074$ method; and (b) determination of $\mathrm{E}_{\mathrm{a}}$ from plot of $\ln (\mathrm{k})$ versus 1/T using modified ASTM C 1074 method. 
quite well. Ma et al. ${ }^{7}$ published the following $E_{a}$ values: Type I cement $=39,000 \mathrm{~J} / \mathrm{mol} ; 17 \%$ Class $\mathrm{F}$ fly ash $=$ $26,700 \mathrm{~J} / \mathrm{mol} ; 8 \%$ silica fume $=30,400 \mathrm{~J} / \mathrm{mol}$; and $65 \%$ GGBFS $=49,300 \mathrm{~J} / \mathrm{mol}$. The values of Ma et al. ${ }^{7}$ compare well with those reported in this study: Type I cement = 40,500 J/mol; $20 \%$ Class F fly ash $=33,200 \mathrm{~J} / \mathrm{mol} ; 5 \%$ silica fume $=31,100 \mathrm{~J} / \mathrm{mol}$; and $50 \%$ GGBFS $=39,900 \mathrm{~J} / \mathrm{mol}$. The largest discrepancy is found between the mixtures with GGBFS, perhaps in part due to the differences in cement type, GGBFS dosages and source. More testing is needed to verify this difference for different cements and GGBFS dosages. Finally, the addition of an accelerator reduces $E_{a}$ for mixtures with fly ash F2 and fly ash C1.

\section{CONCLUSIONS}

Three methods for the calculation of $E_{a}$ are presented to account for the effect of temperature on the overall rate of hydration of cementitious materials. Each method has advantages and disadvantages. The linear method is relatively straight forward, and is quite intuitive. The maximum reaction rate is fairly easy to identify when the specimens are cured at high temperatures as a clearly discernable peak signifies the end of the acceleration phase. The method is highly subjective at low curing temperatures, however, and multiple activation energy values for certain mixtures could be obtained. The subjectivity of this method limits the conclusions that may be drawn about the temperature sensitivity of a particular mixture, as well as the accuracy of any prediction. In addition, only data from the acceleration phase is used to characterize the maximum rate of hydration.

The incremental method, first proposed by KadaBenameur et al. ${ }^{9}$ is the most accurate over the duration of an isothermal calorimetry test. This method provides a tool for the researcher to draw conclusions about the temperature sensitivity of different stages of cement hydration. Activation energy may be calculated up to a degree of hydration of approximately 0.5 . The incremental method, however, is difficult to model mathematically. D'Aloia and Chanvillard ${ }^{8}$ attempted to model activation energy continuously with some success. Work of this nature is useful for study of fundamental reaction mechanism of cementitious materials but requires extensive testing in addition to calorimetry to be accurate. Therefore, the incremental method of activation energy calculation is not convenient for quantifying a wide variety of different mineral and chemical admixtures, nor is it good for constitutive modeling purposes.

The modified ASTM C 1074 method is the best compromise between accuracy and practicality. The accuracy of the method is nearly as good as the incremental method, but it is much easier to model with a three-parameter exponential model. The modified ASTM C 1074 method provides a systematic method to account for the effect of temperature on the combined rate of hydration of cementitious materials.

\section{ACKNOWLEDGMENTS}

The authors would like to extend their appreciation and gratitude for the financial support provided by the Texas Department of Transportation. The advice and support of R. Browne is greatly appreciated.

\section{REFERENCES}

1. Schindler, A. K., "Effect of Temperature on Hydration of Cementitious Materials," ACI Materials Journal, V. 101, No. 1, Jan.-Feb., 2004, pp. 72-81.

2. Saul, A. G. A., "Principles Underlying the Steam Curing of Concrete at Atmospheric Pressure," Magazine of Concrete Research, V. 2, No. 6, Mar., 1951, pp. 127-140.

3. ASTM C 1074, "Standard Practice for Estimating Concrete Strength by the Maturity Method," ASTM International, West Conshohocken, Pa., 1998, 8 pp.

4. Van Breugel, K., "Prediction of Temperature Development in Hardening Concrete," Prevention of Thermal Cracking in Concrete at Early Ages, RILEM Report 15, E\&FN Spon, London, 1998, pp. 51-75.

5. Flynn, J. H., “The 'Temperature Integral'-Its Use and Abuse," Thermochimica Acta, V. 300, 1997, pp. 83-92.

6. Kjellsen, K. O., and Detwiler, R. J., "Later-Age Strength Prediction by a Modified Maturity Model," ACI Materials Journal, V. 90, No. 3, MayJune, 1993, pp. 220-227.

7. Ma, W.; Sample, D.; Martin, R.; and Brown, P. W., "Calorimetric Study of Cement Blends Containing Fly Ash, Silica Fume, and Slag at Elevated Temperatures," Cement, Concrete, and Aggregates, V. 16, 1994, pp. 93-99.

8. D'Aloia, L., and Chanvillard, G., "Determining the 'Apparent' Activation Energy of Concrete; $E_{a}$-Numerical Simulations of the Heat of Hydration of Cement," Cement and Concrete Research, V. 32, 2002, pp. 1277-1289.

9. Kada-Benameur, H.; Wirquin, E.; and Duthoit, B., "Determination of Apparent Activation Energy of Concrete by Isothermal Calorimetry," Cement and Concrete Research, V. 30, 2000, pp. 301-305.

10. Copeland, L. E.; Kantro, D. L.; Verbeck, G., "Part IV-3 Chemistry of Hydration of Portland Cement," 4th International Symposium of the Chemistry of Cement, Washington, D.C., 1960, pp. 429-465.

11. De Schutter, G., and Taerwe, L., "Degree of Hydration-Based Description of Mechanical Properties of Early-Age Concrete," Materials and Structures, V. 29, No. 7, 1996, pp. 335-344.

12. Verbeck, G., and Forster, C. W., "The Heats of Hydration of the Cement," Long-Time Study of Cement Performance in Concrete, Chapter 6, Proceedings of the American Society for Testing Materials, V. 50, 1950, pp. 1235-1262.

13. Glasstone, S.; Laidler, K. J.; and Eyring, H., The Theory of Rate Processes: The Kinetics of Chemical Reactions, Viscosity, Diffusion, and Electrochemical Phenomena. McGraw-Hill Book Company, Inc. New York, 1941, $611 \mathrm{pp}$.

14. Chanvillard, G., and D'Aloia, L., "Concrete Strength Estimation at Early Ages: Modification of the Method of Equivalent Age," ACI Materials Journal, V. 94, No. 6, Nov.-Dec. 1997, pp. 520-530.

15. Tank, R. C., and Carino, N. J., "Rate Constant Functions for Strength Development of Concrete," ACI Materials Journal, V. 88, No. 1, Jan.-Feb., 1991, pp. 74-83.

16. Freiesleben Hansen, P., and Pedersen, E. J., "Maturity Computer for Controlling Curing and Hardening of Concrete," Nordisk Betong, V. 1, No. 19,1977 , pp. 21-25.

17. Schindler, A. K., and Folliard, K. J., "Heat of Hydration Models for Cementitious Materials," ACI Materials Journal, V. 102, No. 1, Jan.-Feb., 2005, pp. 24-33.

18. Pane, I., and Hansen, W., "Concrete Hydration and Mechanical Properties under Nonisothermal Conditions," ACI Materials Journal, V. 99, No. 6, Nov.-Dec, 2002, pp. 534-542.

19. ASTM C 150, "Standard Specification for Portland Cement," Annual Book of ASTM Standards, V. 04.01., ASTM International, West Conshohocken, Pa., 2002, 8 pp.

20. ASTM C 618, "Standard Specification for Coal Ash and Raw or Calcined Natural Pozzolans for Use in Concrete," Annual Book of ASTM Standards, V. 04.01., ASTM International, West Conshohocken, Pa., 2003, $3 \mathrm{pp}$.

21. ASTM C 989, "Standard Specification for Ground Granulated BlastFurnace Slag for Use in Concrete and Mortars," Annual Book of ASTM Standards, V. 04.01., ASTM International, West Conshohocken, Pa., 2005, 5 pp.

22. ASTM C 494, "Standard Specification for Chemical Admixtures for Concrete," Annual Book of ASTM Standards, V. 04.01., ASTM International, West Conshohocken, Pa., 2005, 10 pp.

23. Wirquin, E.; Broda, M.; and Duthoit, B., "Determination of the Apparent Activation Energy of One Concrete by Calorimetric and Mechanical Means; Influence of a Super-Plasticizer," Cement and Concrete Research, V. 32, 2002, pp. 1207-1213. 